Article

\title{
Functionalization of Screen-Printed Sensors with a High Reactivity Carbonaceous Material for Ascorbic Acid Detection in Fresh-Cut Fruit with Low Vitamin C Content
}

\author{
Ylenia Spissu ${ }^{1}\left(\mathbb{D}\right.$, Antonio Barberis ${ }^{1, *}{ }^{\mathbb{C}}$, Gianfranco Bazzu ${ }^{1}$, Guy D'hallewin ${ }^{1}$, Gaia Rocchitta ${ }^{2} \mathbb{C}$, \\ Pier Andrea Serra ${ }^{2}$, Salvatore Marceddu ${ }^{1}$, Claudia Vineis ${ }^{3}\left(\mathbb{D}\right.$, Sebastiano Garroni ${ }^{4}$ (D) and Nicola Culeddu ${ }^{5}$ (D) \\ 1 Institute of Sciences of Food Production, National Research Council, 07100 Sassari, Italy; \\ yspissu82@gmail.com (Y.S.); gbazzu@uniss.it (G.B.); guy.dhallewin@cnr.it (G.D.); \\ salvatore.marceddu@cnr.it (S.M.) \\ 2 Department of Medical, Surgical and Experimental Medicine, Medical School, University of Sassari, \\ 07100 Sassari, Italy; grocchitta@uniss.it (G.R.); paserra@uniss.it (P.A.S.) \\ 3 Institute of Intelligent Industrial Technologies and Systems for Advanced Manufacturing (CNR-STIIMA), \\ National Research Council of Italy, 13900 Biella, Italy; claudia.vineis@stiima.cnr.it \\ 4 Department of Chemistry and Pharmacy, University of Sassari, 07100 Sassari, Italy; sgarroni@uniss.it \\ 5 Institute of Biological Chemistry, National Research Council, 07100 Sassari, Italy; nicola.culeddu@icb.cnr.it \\ * Correspondence: antonio.barberis@cnr.it
}

check for updates

Citation: Spissu, Y.; Barberis, A.; Bazzu, G.; D’hallewin, G.; Rocchitta, G.; Serra, P.A.; Marceddu, S.; Vineis, C.; Garroni, S.; Culeddu, N. Functionalization of Screen-Printed Sensors with a High Reactivity Carbonaceous Material for Ascorbic Acid Detection in Fresh-Cut Fruit with Low Vitamin C Content. Chemosensors 2021, 9, 354. https:// doi.org/10.3390/chemosensors9120354

Academic Editor:

Nicole Jaffrezic-Renault

Received: 31 October 2021

Accepted: 9 December 2021

Published: 11 December 2021

Publisher's Note: MDPI stays neutral with regard to jurisdictional claims in published maps and institutional affiliations.

Copyright: () 2021 by the authors. Licensee MDPI, Basel, Switzerland. This article is an open access article distributed under the terms and conditions of the Creative Commons Attribution (CC BY) license (https:// creativecommons.org/licenses/by/ $4.0 /)$.

\begin{abstract}
In this study, carbon screen-printed sensors (C-SPEs) were functionalized with a high reactivity carbonaceous material (HRCM) to measure the ascorbic acid (AA) concentration in freshcut fruit (i.e., watermelon and apple) with a low content of vitamin C. HRCM and the functionalized working electrodes (WEs) were characterized by SEM and TEM. The increases in the electroactive area and in the diffusion of AA molecules towards the WE surface were evaluated by cyclic voltammetry (CV) and chronoamperometry. The performance of HRCM-SPEs were evaluated by CV and constant potential amperometry compared with the non-functionalized C-SPEs and MW-SPEs nanostructured with multi-walled carbon nanotubes. The results indicated that SPEs functionalized with $5 \mathrm{mg} / \mathrm{mL}$ of HRCM and $10 \mathrm{mg} / \mathrm{mL}$ of MWCNTs had the best performances. HRCM and MWCNTs increased the electroactive area by 1.2 and 1.4 times, respectively, whereas, after functionalization, the AA diffusion rate towards the electrode surface increased by an order of 10 . The calibration slopes of HRCM and MWCNTs improved from 1.9 to 3.7 times, thus reducing the LOD of C-SPE from 0.55 to 0.15 and $0.28 \mu \mathrm{M}$, respectively. Finally, the functionalization of the SPEs proved to be indispensable for determining the AA concentration in the watermelon and apple samples.
\end{abstract}

Keywords: graphene; screen-printed sensors; multi-walled carbon nanotubes; ascorbic acid; LOD; diffusion rate; fresh-cut produce

\section{Introduction}

The scientific community has long recognized the concentration of ascorbic acid (AA) as an effective indicator of quality depletion in fresh-cut produce, since it is an effective radical scavenger of ROS produced by oxidative stress and quickly changes according to non-optimal post-harvest conditions [1-3]. Previous works have focused on monitoring systems built to alert producers or sellers of small variations in the AA concentration caused by unexpected interruptions in the cold chain. Such a variations can have different kinetics in minimally processed fruit and vegetables, but an AA decay always corresponds to a decline in their nutritional value, even in correct storage conditions [1,3-8].

Electrochemical sensors have been demonstrated to be reliable for real-time AA detection, and for the evaluation of the oxidative stability and nutritional quality of fruit and vegetables $[9,10]$. Among them, screen-printed sensors (SPEs) combine the robustness and high repeatability of the measurements and can be easily used in uncomfortable 
environments by unskilled personnel [8]. Unfortunately, carbon electrodes do not always have the necessary requirements to achieve certain objectives; this was the case in [11], where the authors were not able to completely separate the AA and the polyphenol signals and had to resort to the use of fullerenes and nanotubes to increase the sensitivity and specificity of the working electrode [12]; or as in [13], where carbon nanotubes (CNTs) were used to obtain a lower-potential electrocatalytic detection and, hence, a higher selectivity by minimizing the contributions from co-existing electroactive constituents in glucose analysis.

The decay of AA in fresh-cut produce is rapid and, if the cold chain is not respected, its concentration can vary from a minimum of $15 \%$ up to over $60 \%$ of the initial value in just $24 \mathrm{~h}$, depending on the reason that led to the deviation from the correct storage conditions $[4,8]$. The most extreme AA variations can be monitored in real time with carbon screen-printed sensors (C-SPEs) if the AA concentration of fresh produce is high [8], but when it is low, after a few days of storage, the AA oxidation recorded current can be confused with the background noise of the sensor. In such a situation, C-SPEs show limitations due to the fact of their high limit of detection (LOD), the AA low diffusion rate (D) towards the working electrode, and the need for a sufficiently diluted sample to be analyzed. The LOD of a sensor is an analyte concentration that is large enough to produce a current signal larger than the background noise, the current recorded in the absence of the analyte [14]. The LOD depends on the roughness of the working electrode, which changes according to the material from which it is made or with which it is functionalized [15-17]. The diffusion rate can vary according to the concentration of the analyte or to the different applied potentials, and it can be increased by functionalizing bare carbon sensors with different nanomaterials [18-20]. Clearly, such a functionalization will increase the electroactive area of the carbon sensors [19,21].

Although the literature and the market offer a wide variety of nanomaterials that could obviate the aforementioned limitations of C-SPEs, the sector to which this work is addressed needs a low-cost material. Single-walled and multi-walled carbon nanotubes, with a surface area which ranges from 150 to $1500 \mathrm{~m}^{2} / \mathrm{g}$, have high adsorption capacity and rapid desorbability, being excellent candidates for sensing applications [22]. They can be covalently or non-covalently functionalized with several organic molecules that provide a more selective interaction with analytes [23] to promote electron-transfer reactions with enzymes and to fabricate sensors and biosensors with improved performances [24-27]. Their applicability for measuring AA content, phenolic compounds, and for the screening of total antioxidant capacity $[11,12,28,29]$ has been proved. But they are not low cost.

Graphene, on the other hand, represents one of the most used materials as an electrode modifier that dramatically improve the performance of several electrochemical systems. It promotes a rapid electron transfer that facilitates accurate and selective detection of various molecules including AA [30]. Graphene is made from graphite that comes in the form of overlapping layers held together by the weak intermolecular Van der Waals interactions. This makes it easily flaky in a direction parallel to the crystalline plane. Graphene's properties were well summarized in a recent review [31], but the reported properties refer to an almost "ideal" material, completely free of structural defects, and extremely expensive and difficult to produce [32]. Recently, however, production techniques have progressively improved, reducing costs and the complexity of the process, and they have given rise to several chemically modified graphenes, classified as "graphene-like materials" [33]. They do not have the same performances as Geim's and Novoselov's graphene [34,35], since they make use of cheap graphite as a raw material and, therefore, contain a number of impurities. Graphene-like materials include not only single-layer graphene but also microtubules of graphene, graphene oxide, reduced graphene oxide, graphene nanosheets, graphene nanoribbons, and graphene dots, either single- or multi-layered with dimensions [33,36]. They are considered to be the most promising nanomaterials for electrochemical sensing applications, not only for their low cost but also due to the defects created on the graphene oxide layers that provide graphene oxide's unique properties such as excellent conductivity, large specific surface area, and electrocatalytic activity [37-40]. Screen-printed graphene 
electrodes have attracted attention in electrochemical sensing for their application in real samples analysis [41], such as the simultaneous determination of AA, uric acid, and dopamine [42]; the highly sensitive detection of parathion [43]; herbicide residues [44]; analysis of water contaminants [45].

In this paper, we followed up on our previous research, where the concentration of AA was determined in fresh-cut produce with high contents of vitamin $\mathrm{C}$ by means of C-SPEs [8]. Here, similar C-SPEs were functionalized with a patented high reactivity carbonaceous material (HRCM) in order to improve the performances, electroactive area, LOD, and diffusion rate of the C-SPEs to overcome the aforementioned limitations and to measure AA concentration in fresh-cut fruit with low contents of vitamin C. HRCM and the functionalized surface of the working electrodes were characterized by SEM and TEM images. The performances of the HRCM-SPEs were evaluated by cyclic voltammetry $(\mathrm{CV})$, constant potential amperometry (CPA), and chronoamperometry and compared to those of C-SPEs and MW-SPEs functionalized with multi-walled carbon nanotubes. Finally, the ability of the modified and unmodified SPEs to measure the AA concentration in watermelon and apple samples was tested. Both species, according to the literature [46-49], contain low concentrations of AA.

\section{Materials and Methods}

\subsection{Reagents}

All chemicals were of analytical grade and used as received without any further purification. Solutions were prepared with Milli-Q water (Millipore, Inc. (Burlington, MA, USA); $\Omega=18 \mathrm{M} \Omega / \mathrm{cm}$ ). L-ascorbic acid (99.5\%) (Code: 95209-CAS: 50-81-7) was purchased from Merck (Italy); stock solutions of AA were prepared daily in phosphate buffer (PBS) at pH 6.2 and used to carry out CVs, CPA, and chronoamperometries. The phosphate buffer saline solution was made using $\mathrm{NaCl}(137 \mathrm{mM}), \mathrm{KCl}(2.7 \mathrm{mM}), \mathrm{Na}_{2} \mathrm{HPO}_{4}(8.1 \mathrm{mM})$, and $\mathrm{KH}_{2} \mathrm{PO}_{4}(1.47 \mathrm{mM})$ from Sigma and then adjusted to $\mathrm{pH}$, which is close to $\mathrm{pH} 5.6$ of watermelon juice and compatible with most fruit and vegetables used in the fresh-cut sector. The N,N-dimethylformamide (DMF) and MWCNTs (Code: 724769-CAS: 308068) were purchased from Sigma-Aldrich (Merck, Italy).

\subsection{HRCM and MWCNT Characterization}

The HRCM used in this work was provided by Graphene H.R.C.M s.r.l. (Graphene Hrcm S.r.l. via di Vigna Murata, 1, 00143, Rome-Italy). It was thermochemically derived from graphite with a patented procedure as reported in Patent US 7842271B2 of 30/11/2010 indicated as "Mass Production of Carbon Nanostructures" [50].

The morphological investigation of native HRCM was provided using an SEM investigation performed with a Leica Electron Optics 135 VP SEM instrument (LEO Electron Microscopy Ltd., Cambridge, UK) at an acceleration voltage of $15 \mathrm{kV}$ with a $50 \mathrm{pA}$ current probe at a working distance of approximately $22 \mathrm{~mm}$. The samples were sputter-coated with a gold layer in rarefied argon with an Emitech K550 sputter coater (EM Technologies Ltd., Kent, UK) with a current of $20 \mathrm{~mA}$ for $180 \mathrm{~s}$.

The morphological investigation of MWCNTs, as they were received from Merck, was conducted via an SEM investigation performed with a Zeiss EVO LS 10 environmental scanning electron microscope (ESEM) in a high vacuum mode with a secondary electron detector. The samples were sputter-coated with gold in an Agar Automatic Sputter Coater B7341 sputter coater unit.

Transmission electron microscopy (TEM) images of the HRCM were also acquired using an FEI TECNAI 200 operating at $200 \mathrm{kV}$ working with a field emission electron gun. Before TEM analysis, a few milligrams of powders were dispersed into DMF by ultrasonication for $3 \mathrm{~h}$. Afterwards, the DMF solution was dropped onto copper grids (300 mesh), and the solvent was left to evaporate for $30 \mathrm{~min}$ before the measurements. 


\subsection{Functionalization and Morphological Characterization of SPEs}

The screen-printed sensors used in this work were purchased from GSI Technologies (311 Shore Drive Burr Ridge, IL, USA-www.GSITech.com, accessed on 5 February 2019). Before proceeding with the functionalization of the working electrode (WE), the following preliminary operations were carried out:

- $\quad$ The HRCM was micronized with an ultracentrifugal mill RETSCH ZM 200 (RETSCH GmbH Retsch-Allee 1-5 42781 Haan Germany) for $1 \mathrm{~min}$ at $201.24 \mathrm{~g}$ (6000 rpm with rotor radius $=0.5 \mathrm{~cm}$ ) in order to break the agglomerates and reduce the particles size to $<40 \mu \mathrm{m}$;

- $\quad$ The HRCM and MWCNTs were suspended in DMF in accordance with [51], and the following suspensions were obtained: 5,10 , and $50 \mathrm{mg} / \mathrm{mL}$ of MWCNTs/DMF and 5 and $10 \mathrm{mg} / \mathrm{mL}$ of HRCM/DMF;

- The suspensions were ultrasonicated at a frequency of $45 \mathrm{kHz}$ for $3 \mathrm{~h}$ by an ultrasonic cleaner (USC 1200 DVWR international bvba, sprl B-3001 Leuven);

- Before the deposition of the HRCM and MWCNTs, the surface of the WE of a group of SPEs was activated by 10 cycles of $C V$ at an applied potential $\left(E_{a p p}\right)$ from -1.4 to $+1.7 \mathrm{~V}$ at a scan rate of $100 \mathrm{mV} / \mathrm{sec}$ in a $0.1 \mathrm{M}$ sodium bicarbonate solution [52] to promote nanostructuring. A second group of sensors was instead nanostructured without activation of the transducer.

The functionalization of the C-SPEs with HRCM and MWCNTs was carried out using the drop-casting method as previously described [31], where $2.5 \mu \mathrm{L}$ of HRCM and MWCNT suspensions were dispersed over the carbon WEs. Then, HRCM-SPEs and MW-SPEs were dried in a thermostatic stove (Memmert standard series, EN.CO. Srl, Spinea (VE), Italy) at $40{ }^{\circ} \mathrm{C}$ for $45 \mathrm{~min}$ to facilitate the solvent evaporation and the adhesion of the HRCM and MWCNTs to the WE.

An SEM morphological investigation of the WE of SPEs, before and after functionalization, was performed. Sensors were coated with gold in an Agar Automatic Sputter Coater B7341 sputter coater unit and examined with a Zeiss EVO LS 10 ESEM in the high vacuum mode with a secondary electron detector.

\subsection{Electrochemical Characterization of SPEs}

AA oxidation on the WE surface of the C-SPEs, HRCM-SPEs, and MW-SPEs was studied by CV, constant potential amperometry (PCA), and chronoamperometry (CA). All experiments were carried out with a QuadStat four-channel potentiostat (eDaQ QuadStat, e-Corder 410 and Echem software, eDAQ Europe Poland).

A preliminary electrochemical characterization of the WEs was obtained by $\mathrm{CV}$ of $2 \mathrm{mM} \mathrm{AA}$, performed from $-1 \mathrm{~V}$ to $+1 \mathrm{~V}$ (vs. $\mathrm{Ag} / \mathrm{AgCl}$ pseudo-RE) at a scan rate of $0.1 \mathrm{~V} / \mathrm{s}$, to choose the working potential for calibrations and AA detection in the fresh-cut samples. Additional CVs were carried out from $-0.2 \mathrm{~V}$ to $+0.8 \mathrm{~V}$ in order to study the mechanism of AA oxidation and to calculate the electroactive area (A) of the SPEs. To assess the impact of scan rate on the oxidation process, the following rates were selected: $0.01,0.025,0.05,0.075$, $0.1,0.125,0.2,0.25$, and $0.4 \mathrm{~V}$.

The chronoamperometric analysis for different AA concentrations $(25,50$, and $75 \mu \mathrm{M})$ was performed from 0 to $+0.12 \mathrm{~V}$ ( $\mathrm{E}_{\mathrm{app}}$ value used for CPA and sample analysis) by C-SPEs, MW-SPEs, and HRCM-SPEs vs. Ag/AgCl pseudo-RE, in PBS, according to [53], in order to analyze the decay of the current response and to estimate the AA diffusion rate (D) towards the different WEs.

AA calibrations were carried out by CPA according to [8]: a first aliquot of $70 \mu \mathrm{L}$, containing only PBS (used as supporting electrolyte), was deposited on the sensor surface with a graduated micropipette in order to obtain a baseline. A positive potential of $+120 \mathrm{mV}$ was applied vs. Ag/ AgCl pseudo-RE. Once the baseline current was recorded, the PBS drop was dried with absorbent paper without touching the surface of the sensor. Five subsequent $70 \mu \mathrm{L}$ aliquots of increasing AA ( $L$-ascorbic acid (99.5\%) from Merck, Italy) concentrations $(5,10,20,50$, and $100 \mu \mathrm{M})$ were deposited on and removed from the sensor 
surface using the same technique. The current values were read out every two minutes. Additional AA calibrations in PBS at concentrations near the detection limit $(0.25,0.5,0.75$, $1,1.5,2,2.5$, and $5 \mu \mathrm{M} \mathrm{AA}$ ) were performed with C-SPEs and the HRCM-SPE and MWSPE with the best performances.

Additional experiments to study the effect of sample matrix on the AA current were performed. Watermelon and apple juice samples were spiked with 5, 10, 20, and $50 \mu \mathrm{M}$ of AA (standard addition method). Seventy microliters of the spiked samples were deposited on the WE surface of each SPE, and a linear regression analysis was performed on baseline subtracted data. We performed this analysis in triplicate for all of the investigated SPEs. The slopes of the thus obtained linear regressions were compared to the slopes of L-ascorbic acid standard linear regression at the same concentrations.

\subsection{AA Electrochemical Detection in Real Samples}

Fresh-cut watermelon (Citrullus lanatus (Thunb.) Matsum. and Nakai, 1916) and apple (Malus domestica Borkh., 1803 var. Golden delicious) samples were collected by Fresco \& Pronto S.r.l. (Selargius, CA, Sardinia, Italy), a company specialized in the production of minimally processed fruit and vegetables. Fresh-cut fruit were processed following the HACCP guidelines [54] and packaged in see-through resealable polypropylene trays for foodstuffs. Samples were properly stored at $6{ }^{\circ} \mathrm{C}$ until the expiry date, 4 days from processing. The juice for analyses was obtained by a cold extraction from $100 \mathrm{~g}$ of or fresh-cut watermelon and $100 \mathrm{~g}$ of fresh-cut apple, using a DAYA juice extractor for home appliances (power $200 \mathrm{~W} /$ centrifuge $60 \mathrm{rpm}$ ) (Consumer Electronics S.p.A., Legnano, Italy).

The AA detection was carried out immediately after processing (time 0 ) and at the expiration date (day 4). A chromatographic determination of AA in watermelon and apple samples was performed by HPLC method [55]. The obtained values were used to establish a priori the dilution factor necessary to stay in the concentration range in which the sensor response was linear. The electrochemical detection of AA was performed using QuadStat with C-SPEs, HRCM-SPEs, and MW-SPEs. AA currents (nA) were obtained by simply exposing the screen-printed sensors surface to $70 \mu \mathrm{L}$ of watermelon (diluted 1:5 in PBS) and apple juice (diluted 1:100 in PBS) as previously reported [8].

\subsection{Statistical Analysis}

Statistical analysis was performed by GraphPad Prism 5 for Windows software (GraphPad Software, Inc., La Jolla, CA, 92037, USA). AA currents obtained by SPEs were expressed in nanoamperes or microamperes and given as the mean \pm standard deviation (SD) $(n=4)$ of the absolute oxidation currents (nA or $\mu \mathrm{A}$ ) or baseline subtracted currents $(\Delta \mathrm{nA}$ or $\Delta \mu \mathrm{A})$. After in vitro calibrations, the AA currents were plotted vs. the AA concentration, and the linear regression was calculated. The AA concentration in the watermelon and apple samples were calculated and expressed as the molarity after correction of the dilution factor. Micromolar values were then converted to $\mathrm{mg} / 100 \mathrm{~g}$ in the form usually used on food packaging.

In order to assure the similarity between data obtained by HRCM-SPEs or MW-SPEs vs. C-SPEs, a Student's $t$-test to compare means was performed. Differences among sensors performance were compared by ANOVA using a unifactorial complete randomized block design. Mean comparisons were calculated by Fisher's least significant difference test (LSD) at $p \leq 0.05$.

\section{Results}

\subsection{Morphological Characterization of HCRM and MWCNT and Functionalized SPEs}

The native HRCM, as it was received from the company, and MWCNTs, as obtained from Merck, appeared under the electron microscope in the forms shown in Figure 1. 

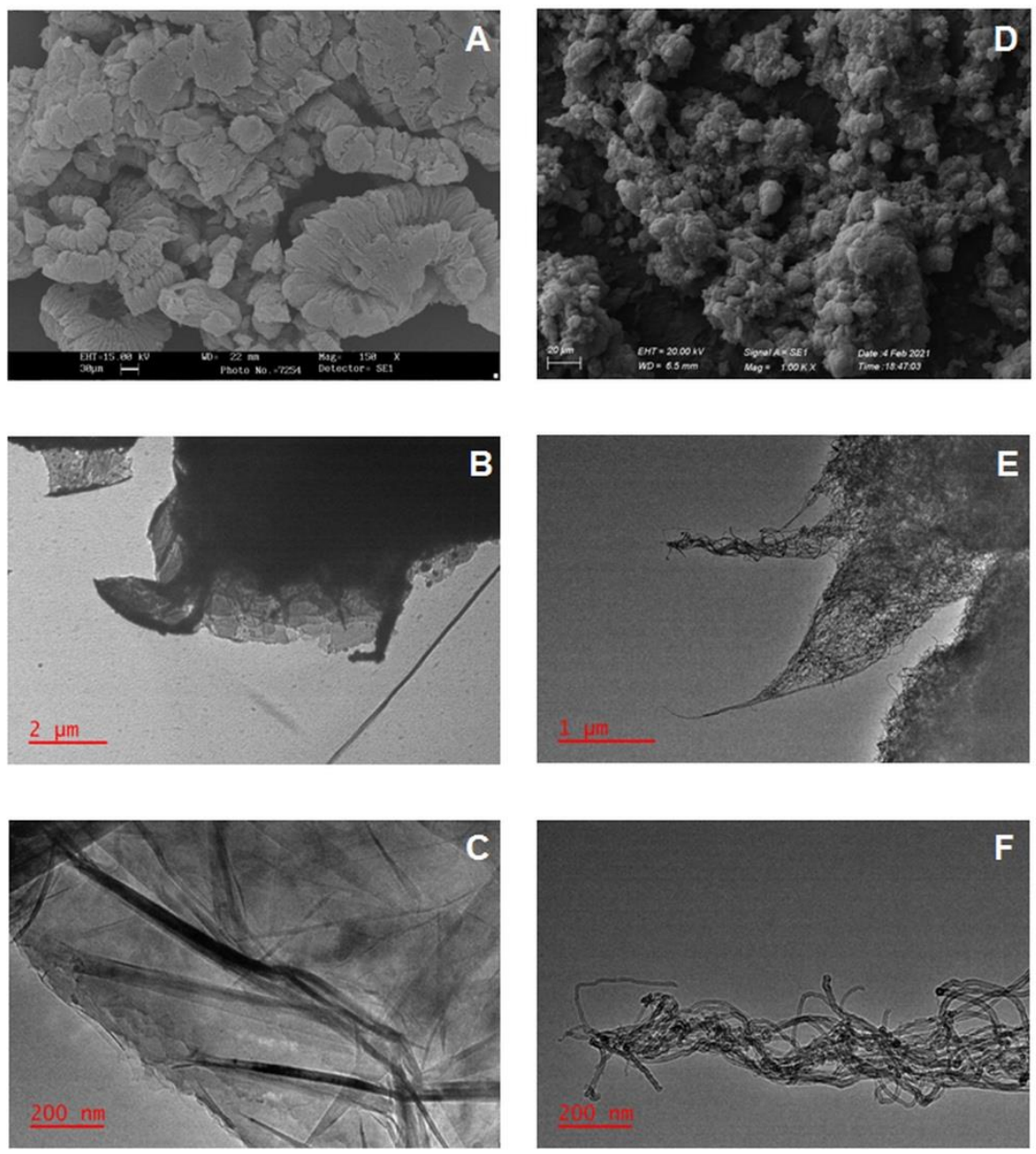

Figure 1. Scanning electron microscope (SEM) images of HRCM (A) and MWCNT (D) agglomerates at different magnifications. $\mathrm{EHT}=$ voltage acceleration $(\mathrm{kV}) ; \mathrm{WD}=$ working distance, the distance between the sample surface and the final lens of the microscope; MAG = magnification, where $X$ corresponds to the magnification; SE1 indicates that the images were collected with the secondary electron detector. Images (A) and (D) were taken by two different SEMs (see Section 2.2) but with the same criteria so as to be comparable. Transmission electron microscopic (TEM) images of HRCM (B,C) and MWCNTs (E,F) after 3 h of ultrasonication. Photographs were taken using an FEI Tecnai 200 TEM, operating at $200 \mathrm{kV}$ working with a field emission electron gun.

The SEM images, both of the HRCM and MWCNTs, show agglomerates of irregular shapes. The HRCM appeared as superimposed two-dimensional sheets (Figure 1A), presumably of graphene, while the MWCNTs as aggregates of spherical structures (Figure 1D). TEM images, taken after $3 \mathrm{~h}$ of ultrasonication, showed the structure of the two nanomaterials more clearly: in the HRCM samples, the systems, shown in Figure 1B,C, possessed morphologic characteristics that typically occur in graphene-based compounds. Overlaid 2D layers, typical of graphene, can clearly be observed together with inclusions of other nanostructures similar to nanotubes, as indicated in the patent [50]. Conversely, in Figure 1E,F, carbon nanotubes with a thickness of $15 \mathrm{~nm}$ can clearly be observed.

The screen-printed sensors used in this work consist of a $4 \mathrm{~mm}$ carbon WE, an $\mathrm{Ag} / \mathrm{AgCl}$ pseudo-reference electrode (RE), and a carbon auxiliary electrode (AE) (Figure 2A). 

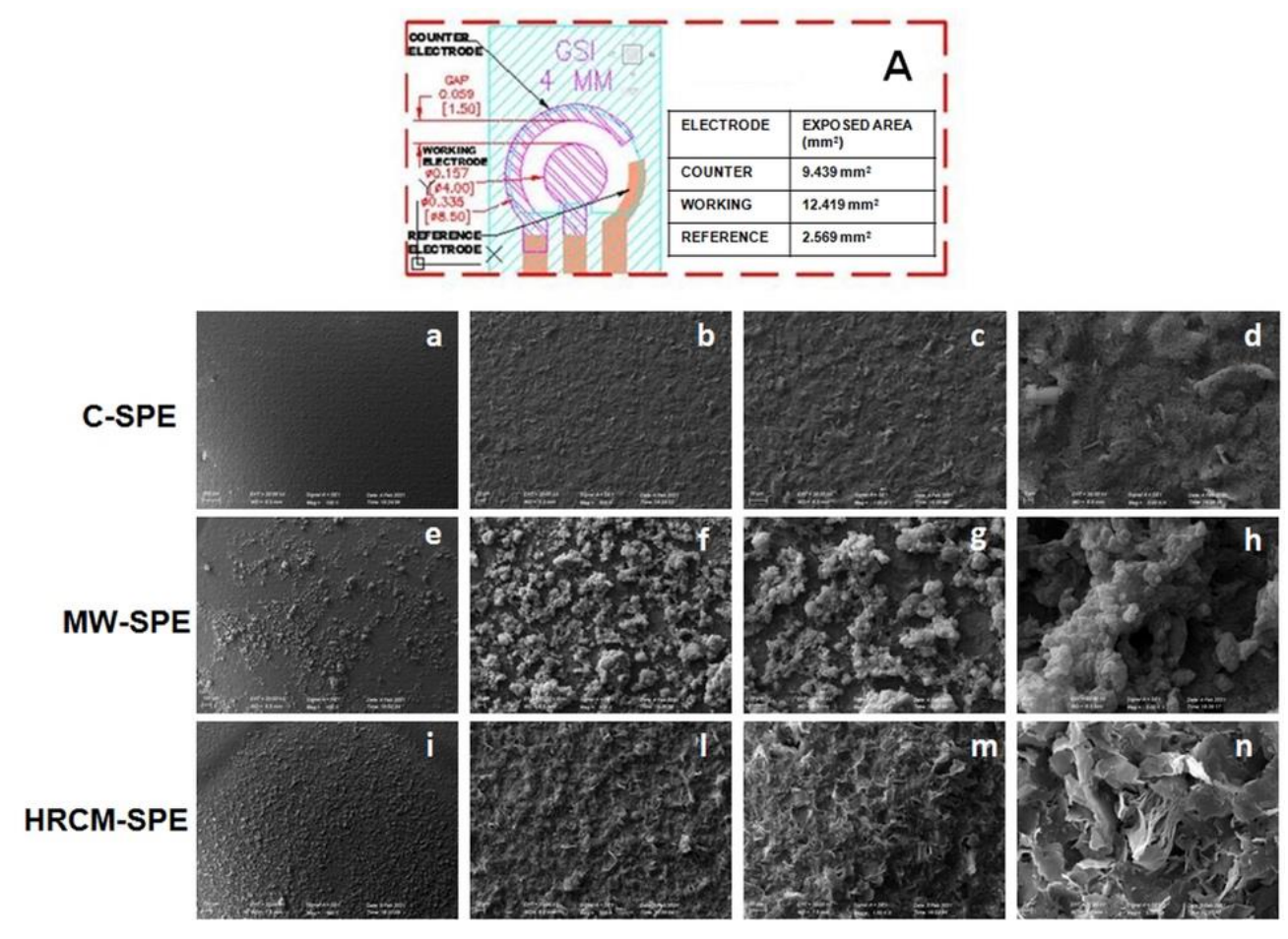

Figure 2. C-SPE schematic drawing (A) with details of working, counter, and reference electrode exposed areas. C-SPE (a-d), MW-SPE (e-h), and HRCM-SPE (i-n) environmental scanning electron microscope (ESEM) images of the WE surface at four different magnifications: (a,e,i) $100 \times,(\mathbf{b}, \mathbf{f}, \mathbf{1}) 500 \times$, $(\mathbf{c}, \mathbf{g}, \mathbf{m}) 1000 \times$, and $(\mathbf{d}, \mathbf{h}, \mathbf{n}) 5000 \times$. EHT $=$ voltage acceleration $(\mathrm{kV}) ; \mathrm{WD}=$ working distance, the distance between the sample surface and the final lens of the microscope; MAG = magnification, where $X$ corresponds to the magnification $(K X=X \times 1000)$; SIGNAL A $=$ SE1 indicates that the images were collected with the secondary electron detector.

The ESEM images of the WE of C-SPE are reported at $100 \times, 500 \times, 1000 \times$, and $5000 \times$ magnifications (Figure 2a,d). They show a homogeneous surface, without smudges or imperfections that alter the amplitude of the transducer area, which can thus provide repeatable current measurements, statistically not different from other identical sensors.

The ESEM images of MW-SPEs are shown in Figure 2e,h. The arrangement of the nanotubes on the WE surface was non-homogeneous, so that aggregates and cavities of different shapes and sizes are evident. It is clear that, even after $3 \mathrm{~h}$ of sonication, the nanotubes tended to re-aggregate quickly.

The ESEM images of HRCM-SPEs are shown in Figure 2i,n. It appears that the micronization and sonication of the HRCM led to a breakdown of the aggregates and the exfoliation of the 2D layers of graphene. They arranged homogeneously on the surface of the WE, without re-aggregating and forming cavities of different shapes and sizes. In this case, the sonication led to a much better dispersion in DMF than the nanotubes.

Different to what was obtained in [52], activation via CV was not required. No statistically significant difference was found between activated and non-activated SPEs.

\subsection{Electrochemical Characterization of SPEs}

3.2.1. Preliminary Investigation of the Voltametric Behavior of AA at Functionalized SPEs

The results of the AA cyclic voltammetries, before and after the functionalization of the C-SPEs with the different suspensions of MWCNTs and HRCM, can be observed in Figure 3. 

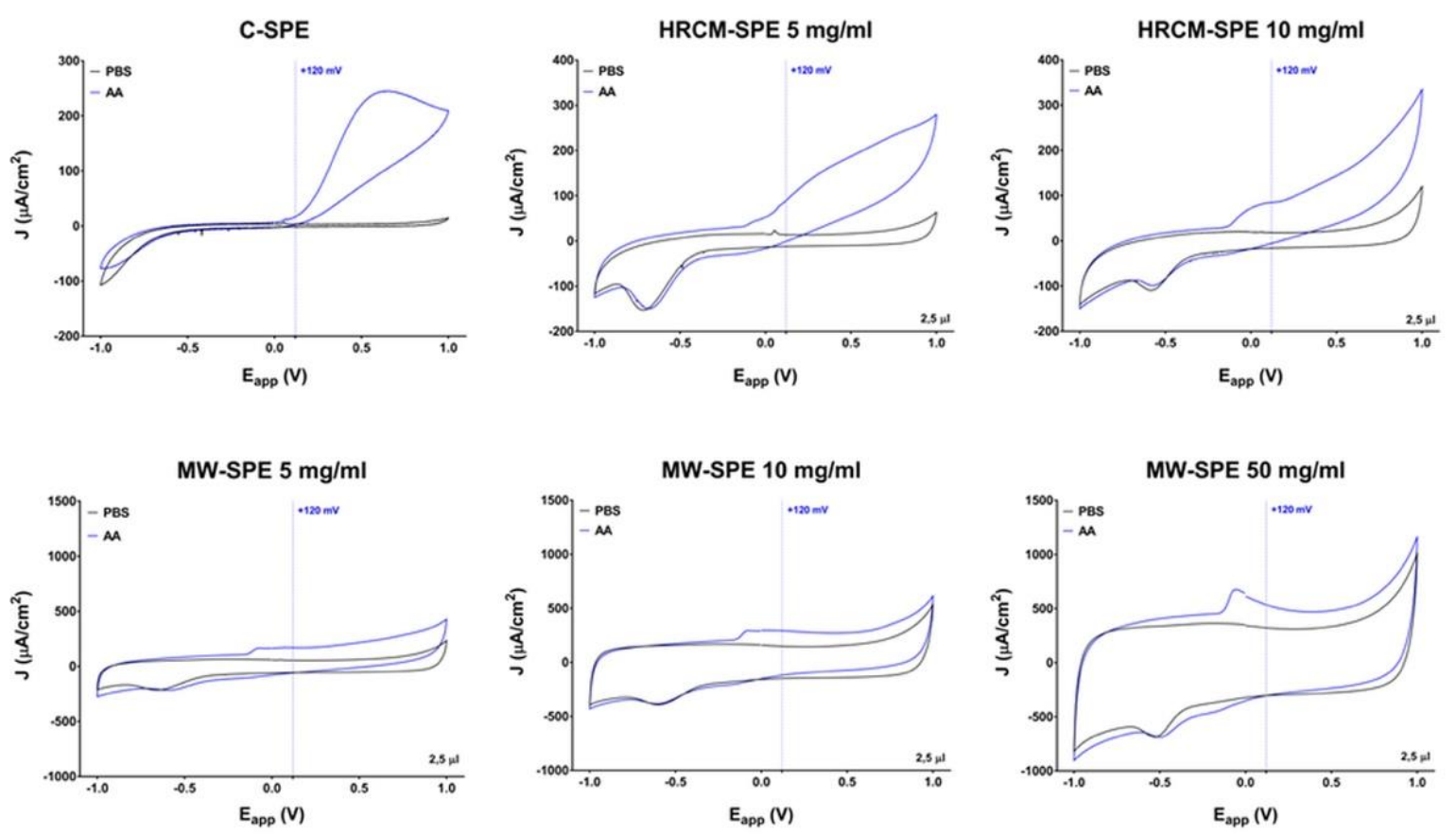

Figure 3. AA cyclic voltammograms with a scanned potential range $\left(\mathrm{E}_{\mathrm{app}}\right)$ between -1 and $+1 \mathrm{~V}$ vs. $\mathrm{Ag} / \mathrm{AgCl} \mathrm{pseudo-RE}$ in the absence (black line) and in the presence of $2 \mathrm{mM} \mathrm{AA}$ (blue line). Cyclic voltammetries were performed with the C-SPE, HRCM-SPEs (functionalized with 5 and $10 \mathrm{mg} / \mathrm{mL} \mathrm{HRCM/DMF),} \mathrm{and} \mathrm{MW-SPEs} \mathrm{(functionalized} \mathrm{with} \mathrm{5,} \mathrm{10,} \mathrm{and} \mathrm{50} \mathrm{mg/mL}$ MWCNTs/DMF).

The voltammograms show that AA was irreversibly oxidized in one step, where two electrons were changing. They also show the effect of the functionalization of the C-SPEs with the different suspensions of HRCM and MWCNTs and the different capacities of the MW-SPEs and HRCM-SPEs to oxidize AA when Eapp changed. In the absence of AA (black line), the voltammograms of the MW-SPEs and HRCM-SPEs differed from those obtained from the C-SPEs, both for the shape and for the recorded current values. The data showed that all the functionalized sensors were able to increase both the baseline and the AA oxidation current (blue line) compared to the C-SPEs. Such an increase varied according to the concentration of the suspension of HRCM or MWCNTs used for the nanostructuring.

Based on the performed voltammograms, and in accordance with previous results $[4,56]$, a potential of $+120 \mathrm{mV}$ was selected as the working potential for calibrations and AA detection in the fresh-cut samples. This value was high enough for a correct reading of AA and, as will be better discussed in Section 3.4., low enough to exclude a large number of molecules that could influence the recorded currents in the real samples. In the histogram of Figure S1 in the Supplementary Materials, the $\Delta$ current (the difference between the AA oxidation current and the baseline current) at $+120 \mathrm{mV}$ was calculated for all sensors. Due to the nanostructuring, both the HRCM-SPEs $(9.337 \pm 0.633 \mu \mathrm{A}$ and $8.279 \pm 0.631 \mu \mathrm{A}$ with the HRCM-SPEs functionalized with 5 and $10 \mathrm{mg} / \mathrm{mL}$, respectively) and the MW-SPEs $(14.607 \pm 1.244 \mu \mathrm{A}, 19.915 \pm 3.262 \mu \mathrm{A}$, and $26.483 \pm 5.501 \mu \mathrm{A}$ with MW-SPEs functionalized with 5,10 , and $50 \mathrm{mg} / \mathrm{mL}$, respectively) recorded significantly higher $\Delta$ current values than the C-SPEs $(1.137 \pm 0.092 \mu \mathrm{A})$.

\subsubsection{Study of the Mechanism of AA Electrochemical Oxidation on the WEs Surface}

Following the analysis in the previous section, additional experiments to study the mechanism of AA electrochemical oxidation on the WE's surface and to calculate the electroactive area of the SPEs were performed. The impact of the scan rate on the AA oxidation process is shown in Figure 4, where cyclic voltammograms of $2 \mathrm{mM} \mathrm{AA}$ at different rates are reported for the C-SPEs and for the HRCM-SPEs functionalized with 
$5 \mathrm{mg} / \mathrm{mL}$ and MW-SPEs functionalized with $10 \mathrm{mg} / \mathrm{mL}$ (those which showed the best performances according to the CVs of Figure 3).
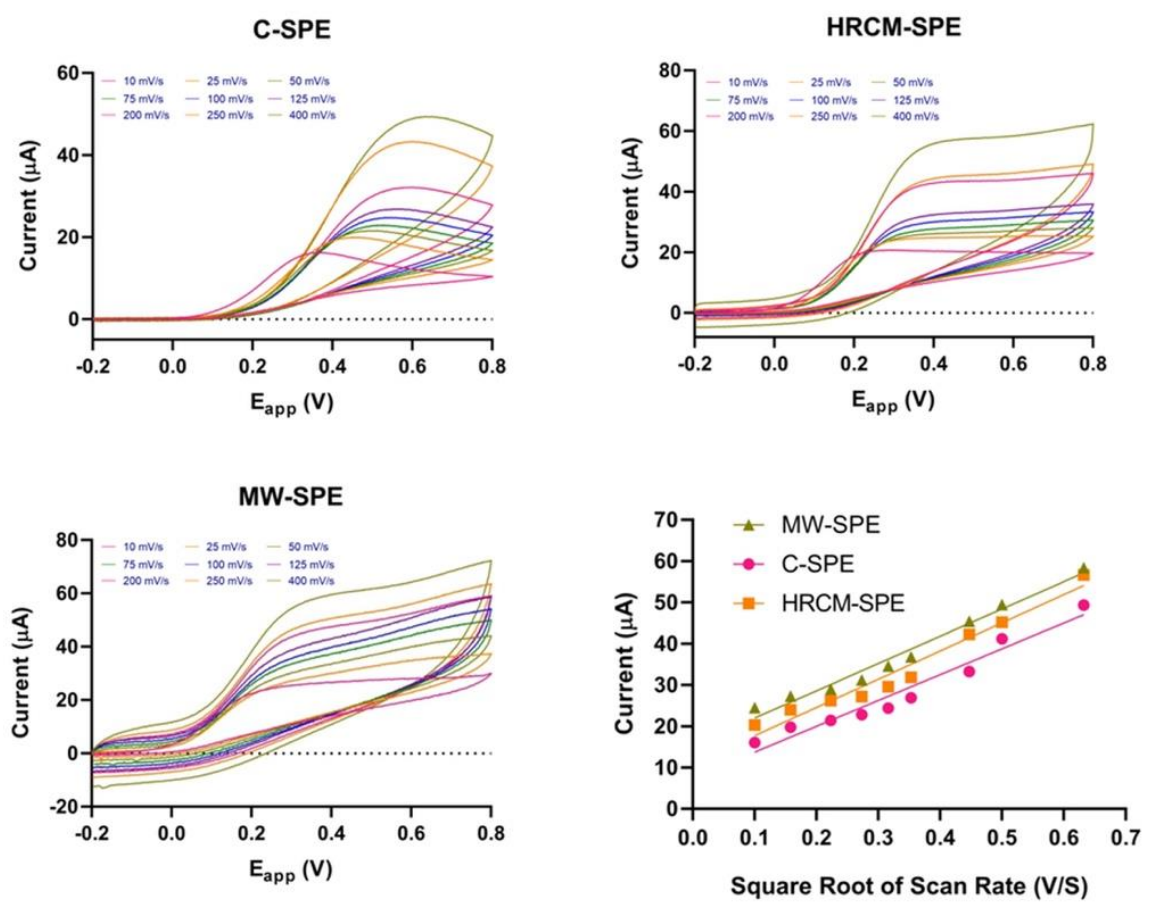

Figure 4. Cyclic voltammograms between a -0.2 and $+0.8 \mathrm{~V}$ potential range $\left(\mathrm{E}_{\mathrm{app}}\right)$ vs. an $\mathrm{Ag} / \mathrm{AgCl}$ pseudo-RE, of $2 \mathrm{mM}$ AA at C-SPEs, HRCM-SPEs, and MW-SPEs with various scan rates of 0.01, $0.025,0.05,0.075,0.1,0.125,0.2,0.25$, and $0.4 \mathrm{~V}$. CVs were performed with the C-SPE and HRCMSPEs functionalized with $5 \mathrm{mg} / \mathrm{mL}$ HRCM/DMF and MW-SPEs functionalized with $10 \mathrm{mg} / \mathrm{mL}$ MWCNTs/DMF. A plot of the AA current $(\mu \mathrm{A})$ versus the $v^{1 / 2}(\mathrm{~V} / \mathrm{s})$ is reported in the lower right part of the figure.

The observed peaks are the results of the AA oxidation. Considering the studied potential scan rate ranging from 0.01 to $0.4 \mathrm{~V} / \mathrm{s}$, the anodic peak current depends linearly on the square root of the scan rate. It is described by the following equations ( $2 \mathrm{mM} \mathrm{AA}$, Figure XD): C-SPE: $I_{p}=62.56(\mathrm{v})^{1 / 2}+7.51, r^{2}=0.9517$; HRCM-SPE: $I_{p}=68.36(\mathrm{v})^{1 / 2}+10.91$, $r^{2}=0.9620$; MW-SPE: $I_{p}=66.12(\mathrm{v})^{1 / 2}+15.39, r^{2}=0.9766$.

These equations may suggest whether the electrode reaction is diffusion or adsorption controlled. Moreover, since the dependence of $\ln \left(I_{p}\right)$ on $\ln (v)$ is characterized by linear regression: C-SPE: $\ln \left(I_{p}\right)=0.5877 \ln (\mathrm{v})+4.01, r^{2}=0.8979$; HRCM-SPE: $\ln \left(I_{p}\right)=0.5411 \ln (\mathrm{v})+4.13, r^{2}=0.8975 ;$ MW-SPE: $\ln \left(I_{p}\right)=0.4768 \ln (\mathrm{v})+4.17, r^{2}=0.9044$. The slope of the fits suggests that the processes are all controlled by diffusion, since they are close to 0.5 [57].

\subsubsection{Calculation of the Electroactive Area of Functionalized SPEs}

The Randles-Sěvcik equation has been used to calculate the electroactive surface area of WE in irreversible electrochemical processes such as AA oxidation $[19,21]$ :

$$
I_{p}=2.69 \times 10^{5} n^{3 / 2} A D^{1 / 2} v^{1 / 2} C
$$

where $I_{p}$ is the anodic peak current, $n$ is the electron transfer number, $A$ is the surface area of the electrode, $D$ is the diffusion coefficient, $v$ is the scan rate, and $C$ is the AA concentration. In this paper: $I_{p}=24.51 \mu \mathrm{A}, 29.69 \mu \mathrm{A}$, and $34.62 \mu \mathrm{A}$ were used for C-SPEs, HRCM-SPEs, and MW-SPEs, respectively; $D=1.42 \times 10^{-6}$ was used according to [21]; $n=2$ was used as previously reported $[19,20] ; v=0.1 \mathrm{~V} / \mathrm{s}$ and $C=2 \mathrm{mM}$. 
The following electroactive areas were calculated: C-SPEs $0.0856 \mathrm{~cm}^{2}$; HRCM-SPEs $0.1037 \mathrm{~cm}^{2}$; MW-SPEs $0.1209 \mathrm{~cm}^{2}$.

\subsubsection{Chronoamperometry}

The chronoamperometric analysis was performed for different AA concentrations in $\mathrm{PBS}$ vs. $\mathrm{Ag} / \mathrm{AgCl}$ pseudo-RE at $+120 \mathrm{mV}$. The results of the chronoamperometries obtained by C-SPEs, HRCM-SPEs functionalized with $5 \mathrm{mg} / \mathrm{mL}$, and MW-SPEs functionalized with $10 \mathrm{mg} / \mathrm{mL}$ were selected to be shown in Figure 5.

\section{C-SPE}
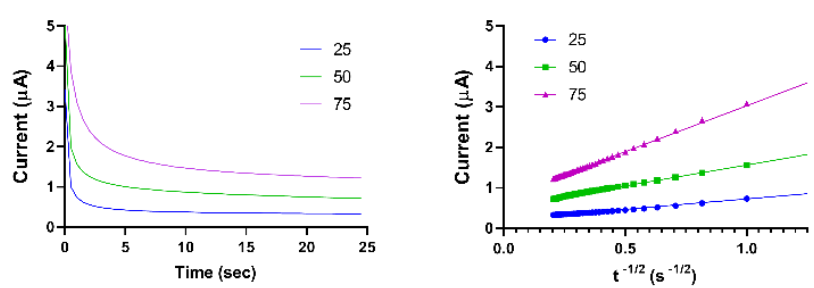

HRCM-SPE
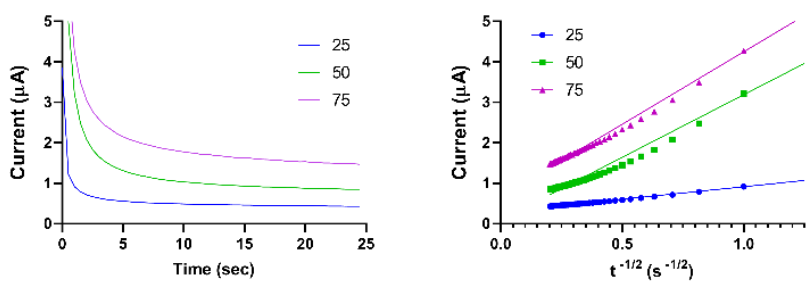

MW-SPE
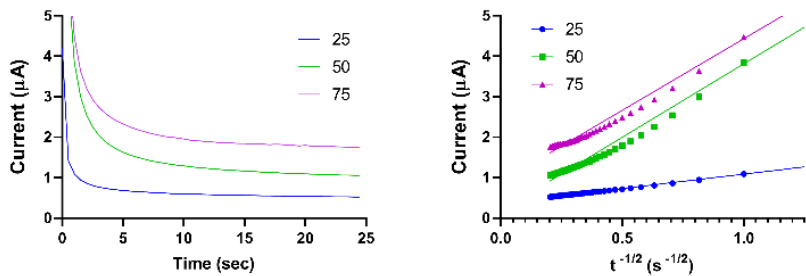

Figure 5. Chronoamperograms of C-SPEs, HRCM-SPEs functionalized with $5 \mathrm{mg} / \mathrm{mL}$, and MW-SPEs functionalized with $10 \mathrm{mg} / \mathrm{mL}$ in PBS at different concentrations of ascorbic acid $(25,50$, and $75 \mu \mathrm{M}$ (graphs on the left)). Cottrell plots of I vs. $\mathrm{t}^{-1 / 2}\left(\mathrm{~s}^{-1 / 2}\right)$ of the chronoamperometric data obtained for 25,50 , and $75 \mu \mathrm{M}$ of AA (graphs on the right).

The Cottrell equation for chronoamperometric analysis of electroactive moieties under mass transfer limited conditions is:

$$
I=n F A D^{1 / 2} c \pi^{-1 / 2} t^{-1 / 2}
$$

where $n$ is the number of electrons involved in the rate determining step ( $n=2$ for AA according to $[19,20]) ; F$ is the Faraday constant of $96,485 \mathrm{C} / \mathrm{mol} ; A$ is the electroactive area of WE of SPEs; $D$ is the diffusion coefficient; $c$ is the (AA), and $t$ is the time (s). According to [53], this equation can be used to estimate the diffusion rate of AA. The slope of the linear region of the $I$ vs. $t^{-1 / 2}$ in the short time region provides the product $A D^{1 / 2}$; thus, $D$ was calculated as $8.17 \times 10^{-11}, 7.76 \times 10^{-10}$, and $4.20 \times 10^{-10} \mathrm{~cm}^{2} / \mathrm{s}$ for C-SPEs, HRCM-SPEs functionalized with $5 \mathrm{mg} / \mathrm{mL}$, and MW-SPEs functionalized with $10 \mathrm{mg} / \mathrm{mL}$, respectively. 


\subsection{AA Calibration, LOD and Aging of SPES}

Figure 6 shows two AA calibration, (A) in the range of 5-100 $\mu \mathrm{M}$, and (B) in the range of 0.25-5 $\mu \mathrm{M}$. In Figure 6A, the linear response of the SPEs was excellent with $r^{2}=0.999$ for C-SPEs and $r^{2}>0.996$ for all the functionalized ones.
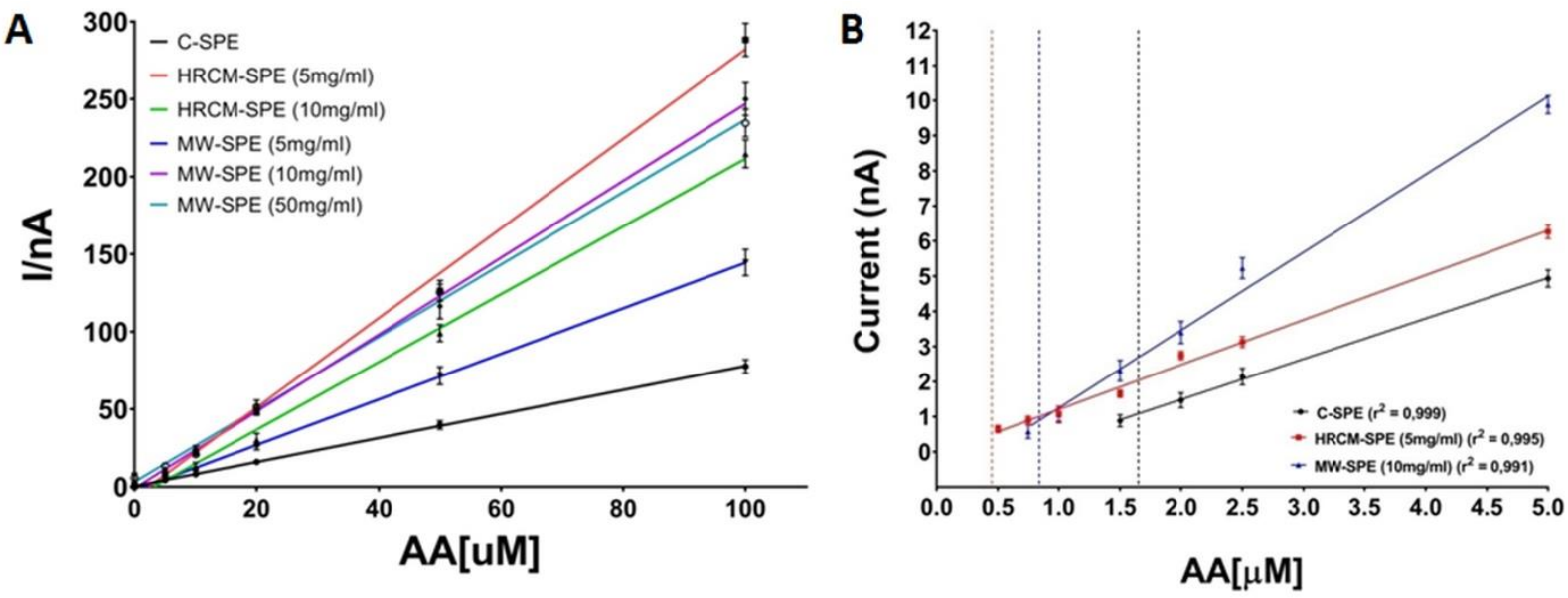

Figure 6. (A) Five-point calibration in PBS with 5, 10, 20, 50, and $100 \mu \mathrm{M}$ AA performed with C-SPEs, MW-SPEs (functionalized with 5, 10, and $50 \mathrm{mg} / \mathrm{mL}$ MWCNTs/DMF), and HRCM-SPEs (functionalized with 5 and $10 \mathrm{mg} / \mathrm{mL} \mathrm{HRCM/DMF).}$ (B) Height-points calibration in PBS with $0.25,0.5,0.75,1,1.5,2,2.5$, and $5 \mu \mathrm{M}$ AA performed with C-SPEs, HRCM-SPEs (functionalized with $5 \mathrm{mg} / \mathrm{mL}$ HRCM/DMF), and MW-SPEs (functionalized with $10 \mathrm{mg} / \mathrm{mL} \mathrm{MWCNTs} / \mathrm{DMF}$ ). All calibrations were baseline subtracted (AA current minus baseline current). An $r^{2}$ value is reported for all calibration lines. Vertical, dashed lines correspond to the LOQ $(3 \times$ LOD) of different SPEs: black line at $\mathrm{x}=1.65 \mu \mathrm{M}$ for C-SPE; red line at $\mathrm{x}=0.45 \mu \mathrm{M}$ for HRCM-SPE; blue line at $\mathrm{x}=0.84 \mu \mathrm{M}$ for MW-SPE. Points outside the linearity range are not displayed on the graph.

The functionalization with HRCM and MWCNTs significantly increased the slope of the C-SPEs (Table 1), thus increasing the ability of the HRCM-SPEs and the MW-SPEs to oxidize the AA compared to C-SPEs.

Table 1. Slope of the AA calibrations $(\mathrm{nA} / \mu \mathrm{M})$ and LOD $(\mu \mathrm{M})$ of the sensors calculated for C-SPEs, HRCM-SPEs functionalized with 5 and $10 \mathrm{mg} / \mathrm{mL}$ of HRCM/DMF suspension, and MW-SPEs functionalized with 5, 10, and $50 \mathrm{mg} / \mathrm{mL}$ of MWCNT/DMF suspension.

\begin{tabular}{ccccccc}
\hline & C-SPE & \multicolumn{2}{c}{ HRCM-SPE } & \multicolumn{2}{c}{ MW-SPE } \\
\hline $\begin{array}{c}\text { Functionali- } \\
\text { zation }\end{array}$ & - & \multicolumn{2}{c}{ mg HRCM/mL of DMF } & \multicolumn{2}{c}{ mg of MWCNTs/mL of DMF } \\
\cline { 2 - 7 } & & 5 & 10 & 5 & 10 & 50 \\
\hline $\begin{array}{c}\text { Slope } \\
(\mathbf{n A} / \mu \mathbf{M})\end{array}$ & $0.77 \pm 0.01 \mathrm{e}$ & $2.89 \pm 0.09 \mathrm{a}$ & $2.18 \pm 0.06 \mathrm{c}$ & $1.47 \pm 0.02 \mathrm{~d}$ & $2.48 \pm 0.04 \mathrm{~b}$ & $2.34 \pm 0.05 \mathrm{~b}$ \\
\hline LOD $(\boldsymbol{\mu M})$ & $0.55 \pm 0.08 \mathrm{c}$ & $0.15 \pm 0.02 \mathrm{e}$ & $0.98 \pm 0.12 \mathrm{~b}$ & $0.53 \pm 0.08 \mathrm{c}$ & $0.28 \pm 0.04 \mathrm{~d}$ & $2.24 \pm 0.27 \mathrm{a}$ \\
\hline
\end{tabular}

Means in row, followed by unlike letters, differed significantly by Fisher's least significant difference (LSD) test $(p \leq 0.05) ;$ n.d. $=$ not detectable since $<\mathrm{LOQ}$. The mean values and standard deviations shown in the table were calculated taking into account the dilution factor.

The LOD of the SPEs was calculated as $3.3 \sigma / \mathrm{S}$, where $\sigma$ is the standard deviation of background noise of the screen-printed sensor, and $S$ is the slope of the linear region of the calibration curve. The LOD values for all of the sensors are also reported in Table 1. The LOQ for all of the SPEs were calculated as $3 \times$ LOD in order to estimate the lowest AA concentration in all of the real samples that could be quantified (see also Section 3.4). The response of SPEs towards low concentrations near the detection limit can be observed in Figure 6B. The results indicated that AA calibrations became linear near the LOQ of the SPEs: $1.65 \mu \mathrm{M}$ for C-SPE, $0.45 \mu \mathrm{M}$ for HRCM-SPE, and $0.84 \mu \mathrm{M}$ for MW-SPE.

The stability of subsequent measurements with SPEs should not be considered, since they are sold in multi-sensors sheets, at a limited price, printed to be used only once. An estimate of the aging of a similar C-SPE and the reproducibility of its measurements has 
already been reported [8]. With the same methodology, the aging and the reproducibility of functionalized SPEs were calculated: a reduction of the slope value by $65 \%$ and $75 \%$ was estimated for HRCM-SPEs and MW-SPEs, respectively, after 10 calibrations with standard AA. As far as reproducibility is concerned, the matrix effect on AA currents was studied: the outcome of the calibration with the standard addition method is shown in Supplementary Materials Figure S2. The deposition of spiked samples on the WE surface of C-SPEs, HRCM-SPEs functionalized with $5 \mathrm{mg} / \mathrm{mL}$, and MW-SPEs functionalized with $10 \mathrm{mg} / \mathrm{mL}$ determined a linear increase in the baseline-subtracted current values. The results, statistically compared with those of AA standard, demonstrated that the exposition to watermelon and apple juice did not affect the SPEs' performances.

\subsection{AA Electrochemical Detection in Watermelon and Apple Juice Samples}

The specificity of the system towards AA was demonstrated in order to eliminate the possibility that the recorded AA currents were influenced by interferers. As reported above, the $E_{\text {app }}$ of $+120 \mathrm{mV}$ was high enough for a correct reading of $\mathrm{AA}$ and low enough to exclude a large number of molecules that could influence the recorded currents in watermelon and apple juice. More than 20 polyphenols were identified in watermelon [58]. The most represented were $p$-coumaric acid, ferulic acid glucuronide, 2,5-dihydroxybenzoic acid, and isoferulic acid glucuronide, all having different redox potentials, but none of them could be a potential interferer since they start to oxidize to a potential higher than $+250 \mathrm{mV}$ [11] and cannot be recorded at $+120 \mathrm{mV}$. Apple polyphenols were prevalently concentrated in the peel $[49,59]$, while only the pulp, where a polyphenols concentration that could affect the AA signal is negligible, was used in this work.

The concentration of AA in the watermelon and apple juice samples was determined by HPLC and by SPEs, and the results are reported and compared in Table 2 . They indicate that the AA concentrations in the watermelon and apple samples could be detected with all sensors and that the data obtained by SPEs did not significantly differ from those obtained with HPLC. Moreover, the data were consistent with the literature [46,49].

Table 2. AA concentration $(\mu \mathrm{M})$ determined in the watermelon and apple samples at time 0 and at the expiration date with HPLC, C-SPEs, HRCM-SPEs functionalized with $5 \mathrm{mg} / \mathrm{mL}$ of HRCM/DMF suspension, and with MW-SPEs functionalized with $10 \mathrm{mg} / \mathrm{mL}$ of MWCNT/DMF suspension.

\begin{tabular}{ccccc}
\hline \multicolumn{5}{c}{ AA Concentration $(\mu \mathrm{M})$ in Watermelon and Apple Samples } \\
\hline HPLC & C-SPEs & HRCM-SPEs & MW-SPEs \\
\hline Watermelon & $153 \pm 6.2 \mathrm{~b}$ & $147 \pm 3.8 \mathrm{~b}$ & $160 \pm 7.1 \mathrm{ab}$ & $165 \pm 7.1 \mathrm{a}$ \\
\hline Apple & $227 \pm 7.7 \mathrm{ab}$ & $219 \pm 6.7 \mathrm{~b}$ & $235 \pm 8.3 \mathrm{a}$ & $240 \pm 7.4 \mathrm{a}$ \\
\hline & & $(\mathrm{AA})$ at expiration date & \\
\hline Watermelon & $73 \pm 5.1 \mathrm{a}$ & $70 \pm 3.7 \mathrm{~b}$ & $71 \pm 5.2 \mathrm{ab}$ & $76 \pm 3.1 \mathrm{a}$ \\
\hline Apple & $102 \pm 5.3 \mathrm{a}$ & n. d. & $99 \pm 6.9 \mathrm{a}$ & $108 \pm 5.5 \mathrm{a}$ \\
\hline
\end{tabular}

Means in row followed by unlike letters differed significantly by Fisher's least significant difference (LSD) test $(p \leq 0.05) ;$ n.d. $=$ not detectable since $<$ LOQ. The mean values and standard deviations shown in the table were calculated taking into account the dilution factor.

All SPEs were able to determine the AA concentration in the watermelon and apple samples at time 0. ANOVA revealed that the MW-SPEs detected a higher AA concentration than the C-SPEs and HPLC, even though the difference was very low and could be considered negligible. The AA mean values obtained by the HRCM-SPEs were consistent with the HPLC and C-SPEs and did not statistically differ from MW-SPEs. According to the HPLC measurements, during the 4 days of cold storage, $52 \%$ and $55 \%$ of the initial AA concentrations were lost for the watermelon and apple samples, respectively.

Although the vitamin C content in the watermelon samples was low, the AA concentration could be detected by the C-SPE both at time 0 and at the expiration date, since 
it was always higher than the LOQ. Otherwise, in the apple samples, the C-SPEs could detect the AA concentration only at time 0 . The reason for this difference was that apple juice could not be directly achieved with the extractor, while a puree was obtained and the puree had to be diluted 1:100 in PBS in order for the $70 \mu \mathrm{L}$ of the sample to be deposited on the sensor's surface. At the expiration date, the $70 \mu \mathrm{L}$ of diluted puree contained approximately $1 \mu \mathrm{M} \mathrm{AA}$, a concentration lower than the LOQ of the C-SPEs $(1.65 \mu \mathrm{M})$. Therefore, it was not possible to distinguish the AA current from the background noise of the C-SPE. But when the HRCM-SPE functionalized with $5 \mathrm{mg} / \mathrm{mL}$ of HRCM/DMF suspension $(\mathrm{LOQ}=0.45 \mu \mathrm{M})$ or the MW-SPEs functionalized with $10 \mathrm{mg} / \mathrm{mL}$ of MWCNT/DMF suspension $(\mathrm{LOQ}=0.84 \mu \mathrm{M})$ were used, the AA concentration at the expiration date was detected because their LODs were low enough.

\section{Discussion}

In previous works $[4,8]$, the quality of fresh-cut produce with a high content of vitamin $\mathrm{C}$ (kiwi, pineapple, and parsley) was monitored by rapid determination of AA, revealing in real time some inefficiencies or malfunctions in the cold chain, allowing operators to intervene and remedy immediately. The sensors used in those works (i.e., pencil rods or carbon screen-printed), allowed for the easy determination of the AA concentration, even when the storage conditions were incorrect.

In this paper, we demonstrated that the functionalization of SPEs with nanomaterials allowed for AA detection in species characterized by a low content of vitamin C. We started by recognizing the main limits of C-SPEs: a small electroactive area, a high LOD, and a relatively low diffusion rate towards the working electrode surface $[8,18-20]$, and we identified a high reactivity carbonaceous material for a low-cost functionalization of C-SPEs. Then, we compared the morphological features and the electrochemical performances of functionalized HRCM-SPEs with those of C-SPEs and SPEs nanostructured with MWCNTs.

The morphological characterization showed that the nature of HRCM was in good agreement with what is reported in the patent [50]. The SEM and TEM images clearly showed superimposed two-dimensional sheets, presumably of graphene, with inclusions of other nanostructures which, according to the patent, are nanofractals, optionally branched open-ended SWNTs, nanoloops, and nanoonions. According to [33], the term "graphenelike materials" is often used in the literature as a common name for two groups of quasi-2D systems with significantly different chemical compositions and properties. The first group, the graphene-based materials, includes systems based on or containing the $0 \mathrm{D} \pm 2 \mathrm{D}$ forms of graphene. These are 2D graphene modified in different manners (by introducing structural vacancies and/or impurities, by adsorption of atoms or molecules, or by mechanical deformation), as well as various hybrid structures formed by graphene with other carbon nanostructures (e.g., graphene \pm fullerene or graphene \pm CNTs), graphene derivatives (graphene oxide, graphane, and fluorographene) or graphene-containing composites. This group also includes graphene ribbons (1D), graphene nano-flakes (0D), and multi-layer graphenes, which can either be modified or used as components of various composites. According to [36], which promoted a precise vocabulary for the family of graphene-based materials, they "consist of not only single-layer graphenes but also fewlayer graphenes, graphene oxide, reduced graphene oxide, graphene nanosheets, ultrafine graphite, graphene ribbons, and graphene dots". We can therefore conclude that the HRCM used in this work is a graphene-based material.

The mere comparison of the SEM images in Figure 2 showed that the functionalization, both with HRCM and MWCNTs, determined a clear increase in the exposed geometric area of the WEs, even though the arrangement of HRCM on the transducer surface was much more homogeneous than MWCNTs. Even though TEM analysis clearly showed carbon nanotubes with a thickness of approximately $15 \mathrm{~nm}$, agglomerates of spherical structures were observed in the SEM images of MWCNTs, and aggregates and cavities of different shapes and sizes were evident on the WEs of the MW-SPEs too. This result is in agreement with our previous work [12] in which both MWCNTs and SWCNTs, after ultrasonication, 
re-aggregated on the surface of the working electrodes, forming agglomerates very similar to those observed in this work. In agreement with [51], we suppose this could depend on the solvent used, even if DMF seemed to be the best solvent among the tested ones (data not shown). According to [60], DMF does not significantly affect the surface of carbon WEs. On the other hand, it proved to be an excellent solvent for HRCM, so that the performances obtained with sensors functionalized with $5 \mathrm{mg} / \mathrm{mL}$ of HRCM were statistically not different from those of sensors functionalized with $10 \mathrm{mg} / \mathrm{mL}$ of MWCNTs. After a series of preliminary tests, most of the experiments in this work focused on these last two SPEs.

If the SEM and TEM images testify to the modification of the geometric surface, the CVs evidenced that the electroactive surface of the WEs were modified following functionalization. It should be noted that the electroactive area of the C-SPEs were found to be smaller than the geometric area by approximately $30 \%$. This is not new, since the ratio $\mathrm{A}_{\text {electroative }} / \mathrm{A}_{\text {geometric }}$ can vary from $75 \%$ to $123 \%$, according to probes, to binder holding the graphite and to carbon black components [21]. The functionalization with HRCM and MWCNTs increased the electroactive area by 1.2 and 1.4 times, respectively, compared to C-SPEs. This is in good agreement with previous works, where the determination of the real electroactive surface of SPEs was investigated by the same technique using the Randles-Sěvcik equation and irreversible probes such as AA $[19,21,61,62]$. In all these papers, it was demonstrated that nanostructuration notably improved the electroactive areas and, as a consequence, the AA oxidation signal. In this work, CVs demonstrated that the presence of the HRCM and MWCNTs on the surface of the WE increased both baseline and AA oxidation currents, generating AA currents 10 and 20 times higher than the C-SPEs, at the potential chosen to carry out the measurements on fruit samples. Furthermore, the linear relation between $I p$ and the square root of the potential scan rate $\left(v^{1 / 2}\right)$ indicated that AA oxidation was a diffusion-controlled process, since it was characterized by a slope value close to 0.5 , while those controlled by adsorption were described by a slope close to 1 [57].

Given that the diffusion rate of the AA towards the WE increased by almost 27 times, just by reducing the geometric C-SPE surface from $0.19547 \mathrm{~cm}^{2}$, used in [8], to $0.12419 \mathrm{~cm}^{2}$ used in this work, functionalization also had another relevant effect: an increase in the electroactive area of HRCM-SPEs and MW-SPEs allowed a remarkable improvement in the diffusion rate by an order of 10 compared to C-SPE. The value of D reported in the manuscript were lower than those commonly reported in the literature, which were of the order of $10^{-6}$ or less [19-21,62]. However, the values in the literature take into account a potential step between $0 \mathrm{mV}$ and the peak value of AA. Differently, the chronoamperometries performed in this manuscript, considered a potential step between 0 and $+120 \mathrm{mV}$, because $+120 \mathrm{mV}$ is the potential used in the analysis of the real samples. For this reason, the current values that we plotted versus $\mathrm{t}^{-1 / 2}\left(\mathrm{~s}^{-1 / 2}\right)$ were much lower than those reported in the literature. The D value of our C-SPEs was compatible with low AA concentrations, bare carbon electrode, and low applied potential, but the functionalization strongly improved the diffusion rate of the SPEs.

The calibrations showed that SPEs functionalized with $5 \mathrm{mg} / 100 \mathrm{~mL}$ of HRCM and $10 \mathrm{mg} / 100 \mathrm{~mL}$ of MWCNTs allowed to obtain the highest currents for the same AA concentration. Although the HRCM concentration used for functionalization was half that of the MWCNTs, the slope in Table 1 indicated that the oxidative capacity of HRCMSPEs and MW-SPEs was 3.7 and 3.2 times higher than the C-SPEs, respectively. Different concentrations, even higher, of the suspensions of HRCM and MWCNTs gave rise to SPEs with lower performances. Moreover, the increase in the slope of the functionalized SPEs is a key point in this work. Since the background noise of the currents generated by modified and unmodified SPEs was quite similar $(\sigma=0.1297$ and 0.1316 for C-SPEs and HRCM-SPEs functionalized with $5 \mathrm{mg} / \mathrm{mL}$, respectively), or even higher ( 0.1987 for MW-SPEs functionalized with $10 \mathrm{mg} / \mathrm{mL}$ ) after the functionalization, the slope values are 
the parameters which mainly define the LOD and LOQ of the SPEs, thus determining the lowest AA concentration that can be detected in watermelon and apple samples.

From a comparison with other publications, where the concentration of AA was determined with SPEs (Table S1 in the Supplementary Materials), it can be stated that sensitivity, linear range, and detection limit of the SPEs used in this work are in line with the literature and with the objectives stated in the introduction. As far as the choice of the most suitable SPE for AA detection in plant species containing low concentrations of vitamin C, a low LOD (and LOQ), linearity near the limit of detection, absence of matrix effect, high electroactive areas, and high diffusion rates are the most important requested parameters. Fruit samples are generally rich in polyphenols and other substances that polymerize on the working electrode of the sensor, the faster the higher the applied potential. This effect, known as "electrode passivation" [63] or the fouling effect, cannot be avoided but has to be minimized [12] with strategies such as the use of the lowest sample concentration as possible; applying the lowest potential possible; reducing the contact time of the SPE surface with the analyte solution; use of an SPE built with material that has the greatest affinity with the analyte of interest, AA in this case. In this work, the functionalization of the sensors with HRCM allowed: for the reduction, with a dilution, of the AA concentration in the samples down to $1 \mu \mathrm{M}$; the application of a potential of $+120 \mathrm{mV}$, to which only AA and a few other molecules, mostly not present in fruit and vegetables [42], could be oxidized; to leave the samples in contact with the transducer for no more than two minutes, so as not to induce the matrix or fouling effect. Finally, as regards the material used for the functionalization, the results suggested that the choice falls either on $5 \mathrm{mg} / \mathrm{mL} \mathrm{HRCM}$ or on $10 \mathrm{mg} / \mathrm{mL}$ MWCNT, which gave similar performances to the relative SPEs. It can be assumed that, in this situation, the choice should fall on the least expensive material.

\section{Conclusions}

The modified SPEs presented in this work showed similar better electrochemical and analytical performances than the unmodified ones. HRCM improved the oxidative capacity of the functionalized SPEs by increasing their electroactive areas. The sensitivity and the diffusion rate of AA towards the transducer surface consistently increased. The limit of detection and of quantification improved. For all these reasons, HRCM can be used for functionalization of SPEs devoted to analyzing fruit and vegetables samples with low content of vitamin C. In particular, the use of HRCM-SPEs is recommended for all the cultivated species when the juice extraction is difficult and/or when the extracts must be previously diluted to be analyzed.

\section{Patents}

Patent US 7842271B2 of 30/11/2010 indicated as "Mass Production of Carbon Nanostructures" [50].

Supplementary Materials: The following are available online at https:/ /www.mdpi.com/article/10 .3390/chemosensors9120354/s1: Figure S1: Effect of functionalization on the AA oxidative capacity of the C-SPEs; Figure S2: Matrix effect on AA currents; Table S1: Sensitivity, linear range, and detection limit of screen-printed sensors for AA detection, a literature selection.

Author Contributions: Conceptualization, A.B., Y.S., N.C. and P.A.S.; methodology, A.B., P.A.S., Y.S. and G.B.; formal analysis, Y.S., A.B., G.B., G.R., C.V., S.M. and S.G.; investigation, A.B. and N.C.; resources, G.D.; data curation, A.B., Y.S., G.B. and P.A.S.; writing-original draft preparation, A.B. and Y.S.; writing—review and editing, A.B., P.A.S., G.D. and Y.S.; supervision, P.A.S.; funding acquisition, G.D. All authors have read and agreed to the published version of the manuscript.

Funding: This research received no external funding.

Institutional Review Board Statement: Not applicable.

Informed Consent Statement: Not applicable. 
Acknowledgments: The authors thank the "Centro Servizi di Ateneo per la Ricerca-CeSAR", University of Sassari.

Conflicts of Interest: The authors declare no conflict of interest.

\section{References}

1. Lee, S.K.; Kader, A.A. Preharvest and Postharvest Factors Influencing Vitamin C Content of Horticultural Crops. Postharvest Biol. Technol. 2000, 20, 207-220. [CrossRef]

2. Santos, J.; Herrero, M.; Mendiola, J.A.; Oliva-Teles, M.T.; Ibáñez, E.; Delerue-Matos, C.; Oliveira, M.B.P.P. Fresh-Cut Aromatic Herbs: Nutritional Quality Stability during Shelf-Life. LWT_Food Sci. Technol. 2014, 59, 101-107. [CrossRef]

3. Gil, M.I.; Amodio, M.L.; Colelli, G. Chapter 7-CA/MA on Bioactive Compounds; Gil, M.I., Beaudry, R.B.T.-C., Fresh, M.A., for Produce, F.-C., Eds.; Academic Press: London, UK, 2020; pp. 131-146. ISBN 978-0-12-804599-2.

4. Barberis, A.; Fadda, A.; Schirra, M.; Bazzu, G.; Serra, P.A. Detection of Postharvest Changes of Ascorbic Acid in Fresh-Cut Melon, Kiwi, and Pineapple, by Using a Low Cost Telemetric System. Food Chem. 2012, 135, 1555-1562. [CrossRef]

5. Spinardi, A.; Ferrante, A. Effect of Storage Temperature on Quality Changes of Minimally Processed of Baby Lettuce. J. Food Agric. Environ. 2012, 10, 38-42.

6. Cocetta, G.; Baldassarre, V.; Spinardi, A.; Ferrante, A. Effect of Cutting on Ascorbic Acid Oxidation and Recycling in Fresh-Cut Baby Spinach (Spinacia Oleracea L.) Leaves. Postharvest Biol. Technol. 2014, 88, 8-16. [CrossRef]

7. Tsironi, T.; Dermesonlouoglou, E.; Giannoglou, M.; Gogou, E.; Katsaros, G.; Taoukis, P. Shelf-Life Prediction Models for Ready-to-Eat Fresh Cut Salads: Testing in Real Cold Chain. Int. J. Food Microbiol. 2017, 240, 131-140. [CrossRef]

8. Spissu, Y.; Barberis, A.; D’hallewin, G.; Orrù, G.; Scano, A.; Serra, G.R.; Pinna, M.; Pinna, C.; Marceddu, S.; Serra, P.A. An Ascorbate Bluetooth $\odot$ Analyzer for Quality Control of Fresh-Cut Parsley Supply Chain. Antioxidants 2021, 10, 1485. [CrossRef]

9. Barberis, A.; Cefola, M.; Pace, B.; Azara, E.; Spissu, Y.; Serra, P.A.; Logrieco, A.F.; D’hallewin, G.; Fadda, A. Postharvest Application of Oxalic Acid to Preserve Overall Appearance and Nutritional Quality of Fresh-Cut Green and Purple Asparagus during Cold Storage: A Combined Electrochemical and Mass-Spectrometry Analysis Approach. Postharvest Biol. Technol. 2019, 148, 158-167. [CrossRef]

10. Barberis, A.; Deiana, M.; Spissu, Y.; Azara, E.; Fadda, A.; Serra, P.A.; D’hallewin, G.; Pisano, M.; Serreli, G.; Orrù, G.; et al. Antioxidant, Antimicrobial, and other Biological Properties of Pompia Juice. Molecules 2020, 25, 3186. [CrossRef] [PubMed]

11. Barberis, A.; Spissu, Y.; Bazzu, G.; Fadda, A.; Azara, E.; Sanna, D.; Schirra, M.; Serra, P.A. Development and Characterization of an Ascorbate Oxidase-Based Sensor-Biosensor System for Telemetric Detection of AA and Antioxidant Capacity in Fresh Orange Juice. Anal. Chem. 2014, 86, 8727-8734. [CrossRef] [PubMed]

12. Barberis, A.; Spissu, Y.; Fadda, A.; Azara, E.; Bazzu, G.; Marceddu, S.; Angioni, A.; Sanna, D.; Schirra, M.; Serra, P.A. Simultaneous Amperometric Detection of Ascorbic Acid and Antioxidant Capacity in Orange, Blueberry and Kiwi Juice, by a Telemetric System Coupled with a Fullerene- or Nanotubes-Modified Ascorbate Subtractive Biosensor. Biosens. Bioelectron. $2015,67,214-223$. [CrossRef]

13. Wang, J.; Musameh, M. Carbon Nanotube Screen-Printed Electrochemical Sensors. Analyst 2004, 129, 1-2. [CrossRef] [PubMed]

14. Desimoni, E.; Brunetti, B. About Estimating the Limit of Detection by the Signal to Noise Approach. Pharm. Anal. Acta 2015, $6,355$.

15. Wang, J.; Tian, B.; Nascimento, V.B.; Angnes, L. Performance of Screen-Printed Carbon Electrodes Fabricated from Different Carbon Inks. Electrochim. Acta 1998, 43, 3459-3465. [CrossRef]

16. Fanjul-Bolado, P.; Hernández-Santos, D.; Lamas-Ardisana, P.J.; Martín-Pernía, A.; Costa-García, A. Electrochemical Characterization of Screen-Printed and Conventional Carbon Paste Electrodes. Electrochim. Acta 2008, 53, 3635-3642. [CrossRef]

17. Talarico, D.; Arduini, F.; Constantino, A.; Del Carlo, M.; Compagnone, D.; Moscone, D.; Palleschi, G. Carbon Black as Successful Screen-Printed Electrode Modifier for Phenolic Compound Detection. Electrochem. Commun. 2015, 60, 78-82. [CrossRef]

18. Baghizadeh, A.; Karimi-Maleh, H.; Khoshnama, Z.; Hassankhani, A.; Abbasghorbani, M. A Voltammetric Sensor for Simultaneous Determination of Vitamin C and Vitamin B6 in Food Samples Using $\mathrm{ZrO}_{2}$ Nanoparticle/Ionic Liquids Carbon Paste Electrode. Food Anal. Methods 2015, 8, 549-557. [CrossRef]

19. He, B.-S.; Zhang, J.-X. Rapid Detection of Ascorbic Acid Based on a Dual-Electrode Sensor System Using a Powder Microelectrode Embedded with Carboxyl Multi-Walled Carbon Nanotubes. Sensors 2017, 17, 1549. [CrossRef]

20. Marian, I.O.; Sãndulescu, R.; Bonciocat, N. Diffusion Coefficient (or Concentration) Determination of Ascorbic Acid Using Carbon Paste Electrodes in Fredholm Alternative. J. Pharm. Biomed. Anal. 2000, 23, 227-230. [CrossRef]

21. García-Miranda Ferrari, A.; Foster, C.W.; Kelly, P.J.; Brownson, D.A.C.; Banks, C.E. Determination of the Electrochemical Area of Screen-Printed Electrochemical Sensing Platforms. Biosensors 2018, 8, 53. [CrossRef]

22. Hussain, C.M.; Mitra, S. Micropreconcentration Units Based on Carbon Nanotubes (CNT). Anal. Bioanal. Chem. 2011, 399, 75-89. [CrossRef]

23. Zhang, B.-T.; Zheng, X.; Li, H.-F.; Lin, J.-M. Application of Carbon-Based Nanomaterials in Sample Preparation: A Review. Anal. Chim. Acta 2013, 784, 1-17. [CrossRef]

24. Pérez-López, B.; Merkoçi, A. Carbon Nanotubes and Graphene in Analytical Sciences. Microchim. Acta 2012, 179, 1-16. [CrossRef]

25. Scida, K.; Stege, P.W.; Haby, G.; Messina, G.A.; García, C.D. Recent Applications of Carbon-Based Nanomaterials in Analytical Chemistry: Critical Review. Anal. Chim. Acta 2011, 691, 6-17. [CrossRef] 
26. Hrapovic, S.; Liu, Y.; Male, K.B.; Luong, J.H.T. Electrochemical Biosensing Platforms Using Platinum Nanoparticles and Carbon Nanotubes. Anal. Chem. 2004, 76, 1083-1088. [CrossRef] [PubMed]

27. Puggioni, G.; Calia, G.; Arrigo, P.; Bacciu, A.; Bazzu, G.; Migheli, R.; Fancello, S.; Serra, P.A.; Rocchitta, G. Low-Temperature Storage Improves the Over-Time Stability of Implantable Glucose and Lactate Biosensors. Sensors 2019, 19, 422. [CrossRef] [PubMed]

28. Lee, Y.-J.; Lyu, Y.-K.; Choi, H.N.; Lee, W.-Y. Amperometric Tyrosinase Biosensor Based on Carbon Nanotube-Titania-Nafion Composite Film. Electroanalysis 2007, 19, 1048-1054. [CrossRef]

29. Amatatongchai, M.; Laosing, S.; Chailapakul, O.; Nacapricha, D. Simple Flow Injection for Screening of Total Antioxidant Capacity by Amperometric Detection of DPPH Radical on Carbon Nanotube Modified-Glassy Carbon Electrode. Talanta 2012, 97, 267-272. [CrossRef]

30. Lawal, A.T. Synthesis and Utilisation of Graphene for Fabrication of Electrochemical Sensors. Talanta 2015, 131, 424-443. [CrossRef]

31. Cinti, S.; Arduini, F. Graphene-Based Screen-Printed Electrochemical (Bio)Sensors and Their Applications: Efforts and Criticisms. Biosens. Bioelectron. 2017, 89, 107-122. [CrossRef]

32. Peplow, M. Graphene: The Quest for Supercarbon. Nature 2013, 503, 327-329. [CrossRef] [PubMed]

33. Ivanovskii, A.L. Graphene-Based and Graphene-like Materials. Russ. Chem. Rev. 2012, 81, 571-605. [CrossRef]

34. Novoselov, K.S.; Geim, A.K.; Morozov, S.V.; Jiang, D.; Zhang, Y.; Dubonos, S.V.; Grigorieva, I.V.; Firsov, A.A. Electric Field Effect in Atomically Thin Carbon Films. Science 2004, 306, 666-669. [CrossRef]

35. Geim, A.K.; Novoselov, K.S. The Rise of Graphene. Nat. Mater. 2007, 6, 183-191. [CrossRef]

36. Wick, P.; Louw-Gaume, A.E.; Kucki, M.; Krug, H.F.; Kostarelos, K.; Fadeel, B.; Dawson, K.A.; Salvati, A.; Vázquez, E.; Ballerini, L.; et al. Classification Framework for Graphene-Based Materials. Angew. Chem. Int. Ed. 2014, 53, 7714-7718. [CrossRef]

37. Huang, X.; Yin, Z.; Wu, S.; Qi, X.; He, Q.; Zhang, Q.; Yan, Q.; Boey, F.; Zhang, H. Graphene-Based Materials: Synthesis, Characterization, Properties, and Applications. Small 2011, 7, 1876-1902. [CrossRef] [PubMed]

38. Compton, O.C.; Nguyen, S.T. Graphene Oxide, Highly Reduced Graphene Oxide, and Graphene: Versatile Building Blocks for Carbon-Based Materials. Small 2010, 6, 711-723. [CrossRef]

39. Song, H.; Zhang, X.; Liu, Y.; Su, Z. Developing Graphene-Based Nanohybrids for Electrochemical Sensing. Chem. Rec. 2019, 19, 534-549. [CrossRef]

40. Zou, Z.; Xi, W.; Hu, Y.; Nie, C.; Zhou, Z. Antioxidant Activity of Citrus Fruits. Food Chem. 2016, 196, 885-896. [CrossRef]

41. Ping, J.; Wang, Y.; Ying, Y.; Wu, J. Application of Electrochemically Reduced Graphene Oxide on Screen-Printed Ion-Selective Electrode. Anal. Chem. 2012, 84, 3473-3479. [CrossRef]

42. Ping, J.; Wu, J.; Wang, Y.; Ying, Y. Simultaneous Determination of Ascorbic Acid, Dopamine and Uric Acid Using HighPerformance Screen-Printed Graphene Electrode. Biosens. Bioelectron. 2012, 34, 70-76. [CrossRef]

43. Mehta, J.; Vinayak, P.; Tuteja, S.K.; Chhabra, V.A.; Bhardwaj, N.; Paul, A.K.; Kim, K.-H.; Deep, A. Graphene Modified Screen Printed Immunosensor for Highly Sensitive Detection of Parathion. Biosens. Bioelectron. 2016, 83, 339-346. [CrossRef] [PubMed]

44. Somnet, K.; Thimoonnee, S.; Karuwan, C.; Kamsong, W.; Tuantranont, A.; Amatatongchai, M. Ready-to-Use Paraquat Sensor Using a Graphene-Screen Printed Electrode Modified with a Molecularly Imprinted Polymer Coating on a Platinum Core. Analyst 2021, 146, 6270-6280. [CrossRef]

45. Materón, E.M.; Wong, A.; Freitas, T.A.; Faria, R.C.; Oliveira, O.N. A Sensitive Electrochemical Detection of Metronidazole in Synthetic Serum and Urine Samples Using Low-Cost Screen-Printed Electrodes Modified with Reduced Graphene Oxide and C60. J. Pharm. Anal. 2021, 11, 646-652. [CrossRef] [PubMed]

46. Yoo, K.S.; Bang, H.; Lee, E.J.; Crosby, K.; Patil, B.S. Variation of Carotenoid, Sugar, and Ascorbic Acid Concentrations in Watermelon Genotypes and Genetic Analysis. Hortic. Environ. Biotechnol. 2012, 53, 552-560. [CrossRef]

47. Bhattacharjee, C.; Saxena, V.K.; Dutta, S. Watermelon Juice Concentration Using Ultrafiltration: Analysis of Sugar and Ascorbic Acid. Food Sci. Technol. Int. 2017, 23, 637-645. [CrossRef] [PubMed]

48. Felicetti, E.; Mattheis, J.P. Quantification and Histochemical Localization of Ascorbic Acid in 'Delicious', 'Golden Delicious', and 'Fuji' Apple Fruit during on-Tree Development and Cold Storage. Postharvest Biol. Technol. 2010, 56, 56-63. [CrossRef]

49. Kim, A.-N.; Lee, K.-Y.; Rahman, M.S.; Kim, H.-J.; Kerr, W.L.; Choi, S.-G. Thermal Treatment of Apple Puree under Oxygen-Free Condition: Effect on Phenolic Compounds, Ascorbic Acid, Antioxidant Activities, Color, and Enzyme Activities. Food Biosci. 2021, 39, 100802. [CrossRef]

50. Petrik, V.I. Mass Production of Carbon Nanostructures. U.S. Patent 7842271B2, 30 November 2010.

51. Manea, F.; Motoc, S.; Pop, A.; Remes, A.; Schoonman, J. Silver-Functionalized Carbon Nanofiber Composite Electrodes for Ibuprofen Detection. Nanoscale Res. Lett. 2012, 7, 331. [CrossRef] [PubMed]

52. Zare, H.R.; Nasirizadeh, N. Fabrication, Characterization and Analytical Performance of the Hydroxylamine Sensor Based on an Oracet Blue Multi-Walled Carbon Nanotubes Film Deposited on an Electrode Surface. J. Braz. Chem. Soc. 2012, 23, 1070-1077. [CrossRef]

53. da Cruz, A.G.B.; Wardell, J.L.; Rocco, A.M. A Novel Material Obtained by Electropolymerization of Polypyrrole Doped with [Sn(Dmit)3]2-, [Tris(1,3-Dithiole-2-Thione-4,5-Dithiolato)-Stannate]2-. Synth. Met. 2006, 156, 396-404. [CrossRef]

54. Regulation (EC) No 852/2004 of the European Parliament and of the Council of 29 April 2004 on the Hygiene of Foodstuffs. Available online: https:/ / eur-lex.europa.eu/legal-content/EN/TXT/?uri=celex\%3A32004R0852 (accessed on 31 October 2021). 
55. Ball, G.F.M. Vitamin C BT-Bioavailability and Analysis of Vitamins in Foods; Ball, G.F.M., Ed.; Springer: Boston, MA, USA, 1998; pp. 517-560, ISBN 978-1-4899-3414-7.

56. Barberis, A.; Bazzu, G.; Calia, G.; Puggioni, G.M.G.; Rocchitta, G.G.; Migheli, R.; Schirra, M.; Desole, M.S.; Serra, P.A. New Ultralow-Cost Telemetric System for a Rapid Electrochemical Detection of Vitamin C in Fresh Orange Juice. Anal. Chem. 2010, 82, 5134-5140. [CrossRef]

57. Suliborska, K.; Baranowska, M.; Bartoszek, A.; Chrzanowski, W.; Namieśnik, J. Determination of Antioxidant Activity of Vitamin C by Voltammetric Methods. Proceedings 2019, 11, 23. [CrossRef]

58. Fan, J.; Park, E.; Zhang, L.; Edirisinghe, I.; Burton-Freeman, B.; Sandhu, A.K. Pharmacokinetic Parameters of Watermelon (Rind, Flesh, and Seeds) Bioactive Components in Human Plasma: A Pilot Study to Investigate the Relationship to Endothelial Function. J. Agric. Food Chem. 2020, 68, 7393-7403. [CrossRef] [PubMed]

59. Alonso-Salces, R.M.; Ndjoko, K.; Queiroz, E.F.; Ioset, J.R.; Hostettmann, K.; Berrueta, L.A.; Gallo, B.; Vicente, F. On-Line Characterisation of Apple Polyphenols by Liquid Chromatography Coupled with Mass Spectrometry and Ultraviolet Absorbance Detection. J. Chromatogr. A 2004, 1046, 89-100. [CrossRef]

60. Blanco, E.; Foster, C.W.; Cumba, L.R.; do Carmo, D.R.; Banks, C.E. Can Solvent Induced Surface Modifications Applied to Screen-Printed Platforms Enhance Their Electroanalytical Performance? Analyst 2016, 141, 2783-2790. [CrossRef]

61. Kalyan Kumar, M.; Sagarika Deepthy, T.; Chirasree Roy, C.; Saha, H. Electrochemical Characterization of Some Commercial Screen-Printed Electrodes in Different Redox Substrates. Curr. Sci. 2015, 109. [CrossRef]

62. Aflatoonian, M.R.; Tajik, S.; Aflatoonian, B.; Beitollahi, H. Electrochemical Measurements of Ascorbic Acid Based on Graphite Screen Printed Electrode Modified with La3+/Co3O4 Nanocubes Transducer. J. Electrochem. Sci. Eng. 2019, 9, 197-206. [CrossRef]

63. Ferreira, M.; Varela, H.; Torresi, R.; Tremiliosi-Filho, G. Electrode Passivation Caused by Polymerization of Different Phenolic Compounds. Electrochim. Acta 2006, 52, 434-442. [CrossRef] 